\title{
ENSINO EM CENA: O USO DE OBRAS CINEMATOGRÁFICAS NO FORTALECIMENTO DA FORMAČ̃̃O ACADÊMICA E DA DIVULGAÇÃO CIENTÍFICA
}

\author{
Anderson Pereira Rodrigues; Samantha Macedo Lima; Danilo Sousa Rocha. \\ anderson.pereira@ifce.edu.br; samanthapedagoga@gmail.com; danilo@fisica.ufc.br \\ Instituto Federal de Educação, Ciência e Tecnologia do Ceará (IFCE) - Campus Sobral \\ DOI:10.15628/diálogos.2018.6579
}

Artigo submetido em nov/2017 e aceito em jun/2018

\section{RESUMO}

A elaboração de aulas lúdicas faz-se necessária dentro do contexto de sala de aula porque proporciona aos alunos formas visuais de compreensão dos conceitos e da realidade científica que se queria mostrar. Desse modo, a linguagem cinematográfica se configura uma importante ferramenta no processo de ensino-aprendizagem, ao facilitar a compreensão de uma variedade de conceitos através de estímulos sensoriais humanos. Assim, o projeto "Ensino em Cena" do IFCE, campus de Sobral, utiliza dessa ferramenta para auxiliar nesse processo, difundindo e favorecendo a construção do saber. Mensalmente, os professores, apresentam para o público um filme que envolva os temas: ciências, ensino, tecnologia, filosofia e arte. Ao término da apresentação do longa, os espectadores podem participar de um breve debate, a fim de esclarecer qualquer pormenor acerca do conteúdo abordado. A boa recepção e a compreensão do conteúdo pelos espectadores em cada apresentação demonstraram que ferramentas lúdicas como o cinema podem ser alternativas viáveis na luta a favor da atenção do aluno e da curiosidade do educando.

PALAVRAS-CHAVE: Educação. Cinema. Divulgação Científica.

\section{INTRODUÇÃO}

O uso de obras cinematográficas como recurso didático motivacional já é uma ideia bem antiga, mas nem sempre foi abraçada. De acordo com Leite (2005), a relação entre o cinema e a educação brasileira data desde os anos de 1920. Há registros do início do século XX que demonstram a existência de muitas dúvidas a respeito da eficácia do uso de filmes como ferramenta educacional. Em 1930, por exemplo, os professores Jonathas Serrano e Francisco Venâncio Filho, que ajudaram a subsidiar a criação do INCE (Instituto Nacional de Cinema Educativo), escreveram o livro intitulado "Cinema e Educação". Nesse, os autores afirmam que o 
professor via com desinteresse e desconfiança o uso do cinema escolar. Tais receios podem ter dificultado a formação de uma cultura positiva sobre o uso de filmes na educação (CARVALHAL, 2009). Em 1931, Roberto Assumpção, no seu livro “O Cinema Sonoro e a Educação", argumenta sobre o receio que o mestre tinha sobre a utilização do filme a respeito da eficácia do filme como recurso didático. Sobre isso, a metodologia de ensino, utilizando o recurso da linguagem cinematográfica, inicialmente não foi muito bem aceita entre os educados porque os filmes, até então, eram destinados ao lazer e contemplação da arte, por isso, os educadores tinham dúvidas sobre a capacidade e eficácia dos filmes de propiciar uma aprendizagem de conceitos científicos. O que está bem evidente, no livro "Cinema contra Cinema" do cineasta Joaquim Canuto Mendes de Almeida, com o qual, não há informações quanto à receptividade por parte dos educadores, apesar de o autor indicar que o professor deveria ser o responsável pela condução dos filmes (CARVALHAL, 2009).

Contundo, no início dos anos 90, com o processo ampliado de globalização, novas tecnologias da informação e da comunicação, aliado ao movimento de reformas na educação no Brasil e no mundo, esse cenário foi promissor para o debate da educação e de sua articulação dos processos formativos com as tecnologias de comunicação e informação. Assim, pode-se assegurar que a linguagem cinematográfica integrou o conjunto de metodologias de ensino e aprendizagem.

Nesse contexto, a linguagem cinematográfica se constituiu como uma mídia, uma linguagem artística extremamente acessível, que está presente facilmente no cotidiano das pessoas. Desta forma, o cinema pode ser utilizado como uma ferramenta para potencializar o processo ensinoaprendizagem. Para Duarte (2002, p. 17), por exemplo, "ver filmes é uma prática social tão importante, do ponto de vista da formação cultural e educacional das pessoas, quanto a leitura de obras literárias, filosóficas, sociológicas e tantas mais."

Ainda neste sentido, Verde argumenta:

O cinema, com sua linguagem própria, concretiza sonhos e devaneios. Constrói e dissolve valores, possibilita novas experiências através de exemplificações, edifica novas relações espaciais puramente virtuais, por isso mais significativas que as vividas na realidade cotidiana (VERDE, 2005, p. 44).

Visando um melhor aproveitamento dos muitos recursos que o cinema oferece, o Projeto de extensão "Ensino em Cena", realizado pelo Curso de Licenciatura em Física do IFCE campus de Sobral, consiste em possibilitar aos alunos a integração das artes visuais com as disciplinas curriculares, a fim de facilitar a integração das mesmas, favorecendo o aprendizado dos conteúdos ministrados. A ideia visa abrir um espaço entre o quadro e as carteiras, iluminando como um foco de luz sobre a tela branca, a iniciativa de brincar com o saber, aprendendo a ensinar e ensinando a aprender. Tal ação de extensão vem sendo apresentada a comunidade sobralense desde agosto de 2015. 
O Projeto "Ensino em Cena" é destinado aos alunos do ensino médio, técnico, tecnológico e superior das redes pública e privada da região norte do estado do Ceará, bem como aos curiosos, professores e educadores que acreditam e apostam no potencial pedagógico e educacional que o cinema pode oferecer.

Desse modo, esse projeto objetiva-se em consolidar e dar visibilidade a uma metodologia de trabalho alternativa e complementar para os alunos, para que eles possam usufruir da linguagem cinematográfica como instrumento para difundir, favorecer, facilitar e potencializar a construção do conhecimento, a partir de sessões cinematográficas e debates sobre os conceitos científicos e educacionais abordados no filme apresentado, além de apresentar o cinema como uma metodologia de ensino em ciência e um forte recurso didático-pedagógico.

\section{FUNDAMENTAÇÃO}

Não é de hoje a prática de se utilizar obras da sétima arte como instrumento lúdico para o ensino. Essa já é uma realidade antiga para certas escolas providas com os antigos videocassetes e os atuais aparelhos de DVDs, Blu-ray ou até mesmo computadores conectados a projetores. A modernização fez com que a sala de aula pudesse se transformar facilmente numa sala de cinema. Porém, não são todos os educadores que se identificam ou usam essa mídia como recurso didático-pedagógico. Outros, entretanto, costumam se utilizar de tal ferramenta como agente motivador, ilustrador do conteúdo, ou até mesmo divertimento.

De acordo com Barros, Girasole e Zanella (2013), apesar de toda a transformação, ocorrida na sociedade do conhecimento e da educação, no que tange a facilidade de acesso, o cinema ainda é pouco valorizado pela escola, principalmente pelo fato de não ser compreendido por todos os alunos e educadores como estratégia pedagógica séria e planejada.

De acordo com Caparrós-Lera e Rosa (2013), o emprego da sétima arte no ensino de história é uma prática antiga, conhecida e consolidada. Porém, os autores afirmam que tal ferramenta não está livre de dificuldades e nem de dúvidas. A primeira entre tantas dificuldades enfrentadas é o desconhecimento sobre o cinema e a dúvida recai em como ele pode contribuir no ensino do conteúdo científico. Como já foi citado, desde 1930, no Brasil, o uso do cinema na escola foi palco de um longo debate promovidos por professores, intelectuais e o governo. 0 resultado foi à criação do Instituto Nacional de Cinema Educativo (INCE) destinado a produzir filmes educativos. Desde então, muita coisa mudou, mas o cinema não deixou a sala. Na verdade, ela só ganhou mais espaço.

Conforme Franco (2005 apud SILVA, 2014), a influência do cinema, enquanto mídia, auxiliam na formação de crianças e adolescentes e pode vir a interferir na sociedade, uma vez que tal mídia pode carregar consigo uma grande diversidade de linguagens, costumes, valores e diversos outros elementos educacionais. Dessa forma, o cinema, o teatro, a internet e outras mídias podem ser importantes instrumentos a serviço no processo ensino-aprendizagem, pois "as mídias 
audiovisuais, sejam elas tradicionais ou interativas, têm um papel fundamental como veículos catalizadores para a construção de conhecimento". (FRANCO, 2005 apud SILVA, 2014, p. 363).

\section{METODOLOGIA}

O Projeto "Ensino em Cena" acontece na terceira quarta-feira de cada mês, no auditório do IFCE campus de Sobral. O projeto consiste na apresentação sistemática de filmes de longametragem que se relacionem com o conteúdo estudado em sala de aula e é acompanhado com um breve debate crítico guiado por um professor interlocutor. Essa forma de apresentação incita a participação ativa dos alunos proporcionando um momento para esclarecer qualquer dúvida acerca do conteúdo abordado.

No projeto em questão, os alunos são beneficiados com diversos conteúdos de física, matemática, ciências, ensino, cultura e arte, além de fatos históricos, científicos e bibliográficos das principais descobertas e personalidades que influenciaram a evolução e o desenvolvimento do pensamento científico.

Até a presente data foram exibidos seis longas-metragens em que foi possível observar o crescimento gradual do número de participantes, perfazendo uma média de cinquenta espectadores por sessão, o que demonstra um resultado positivo e um fortalecimento cultural do projeto. Em cada longa-metragem apresentado, uma gama de assuntos, conceitos, teorias, proposições, experiências, etc., relacionados ao filme são comentados e discutidos entre os presentes. Neste momento, há a possibilidade de troca de experiências e conhecimentos, dando voz aos professores, educadores, alunos, bem como à comunidade em geral.

A seguir, a Tabela 1 mostra a lista de filmes apresentados no ano de 2016 e 2017, bem como os pontos abordados pelo professor interlocutor nas discussões após o filme.

Tabela 1 - Filmes apresentados nos anos de 2016 e 2017.

\begin{tabular}{l|l}
\hline \multicolumn{1}{c|}{ Título } & \multicolumn{1}{c}{ Temas Abordados } \\
\hline Interestelar & Relatividade geral; Buraco negro; Buraco de Minhoca; Viagem no tempo. \\
\hline Lucy & $\begin{array}{l}\text { Viagem no tempo; Quantização e existência do tempo; Tempo x Movimento; } \\
\text { Mito do uso de 10\% do cérebro. }\end{array}$ \\
\hline Perdido em Marte & $\begin{array}{l}\text { Colonização espacial; Tempestades Marcianas; Colonização do planeta } \\
\text { vermelho. }\end{array}$ \\
\hline Escritores da Liberdade & $\begin{array}{l}\text { Desigualdades de classes sociais; Racismo; Políticas públicas sem função; } \\
\text { Escola como aparelho reprodutor ideológica; Relação professor x aluno; } \\
\text { Conhecimento como ato revolucionário. }\end{array}$ \\
\hline Teoria de Tudo & $\begin{array}{l}\text { Biografia de Stephen Hawking; Buracos negros; Teoria do Big-Bang; } \\
\text { Singularidade; Teoria da Unificação. }\end{array}$ \\
\hline Matrix & Alegoria da Caverna; Tecnologia; Inteligência artificial; Distopia; Filosofia. \\
\hline O Jogo da Imitação & Biografia de Alan Turing; Lógica matemática; Máquina de Turing; \\
\hline Ghost in the Shell & Técnica; Inteligência artificial; mundo futurístico. \\
\hline Ex-Machina & $\begin{array}{l}\text { Inteligência artificial; Revolução das máquinas; Confronto entre identidades: } \\
\text { Homem x Máquina. }\end{array}$ \\
\hline
\end{tabular}


Para o ano de 2018, o grupo organizador do projeto já elegeu uma lista de filmes a serem exibidos. A Tabela 2 apresenta essa lista, bem como os possíveis assuntos a serem debatidos com os espectadores de cada sessão.

Tabela 2 - Filmes que deverão ser apresentados no ano de 2018.

\begin{tabular}{l|l}
\hline \multicolumn{1}{c|}{ Título } & \multicolumn{1}{c}{ Temas Abordados } \\
\hline Sunshine - Alerta Solar & Atividade solar; Vida e morte das estrelas. \\
\hline Espectral & Guerra; Mundo futurístico. \\
\hline Apollo 13 & Exploração espacial; Força gravitacional; Transformações gasosas. \\
\hline Donnie Darko & Viagem no tempo; determinismo. \\
\hline Contato & Astronomia; Vida extraterrestre \\
\hline Gravidade & Gravitação; Mecânica celeste. \\
\hline
\end{tabular}

A Tabela 3 mostra sugestões de outros filmes e documentários que podem ser usados para aprimorar o uso do cinema como ferramenta pedagógica.

Tabela 3 - Sugestões de filmes e temas abordados.

\begin{tabular}{l|l}
\hline \multicolumn{1}{c|}{ Título } & \multicolumn{1}{c}{ Temas Abordados } \\
\hline A.I. - Inteligência Artificial & Engenharia genética bioética; Tecnologia. \\
\hline Eu, Robô & Engenharia genética bioética; Tecnologia; Inteligência artificial. \\
\hline A Ilha & Clonagem; Genética; Ética; Biotecnologia; \\
\hline Máquina do Tempo & Ecologia; Evolução. \\
\hline Stargate & Teoria da relatividade geral; Buracos de minhoca. \\
\hline Uma Mente Brilhante & Biografia de John Nash; Teoria dos jogos; Saúde mental. \\
\hline Wall-E & Obesidade; Consumismo; Reciclagem. \\
\hline Fed Up & Saúde alimentar; Obesidade. \\
\hline O Núcleo - Missão ao centro da Terra & Colonização espacial. \\
\hline Jurassic Park & Movimentos da Terra; Magnetismo. \\
\hline Ponto de Mutação & $\begin{array}{l}\text { Paleontologia; Evolução; Extinção das espécies engenharia } \\
\text { genética; Bioética e tecnologia. }\end{array}$ \\
\hline Avatar & $\begin{array}{l}\text { Ecologia; Biologia sistêmica; Psicologia; } \\
\text { Sustentabilidade; Guerra; Filosofia; Política. }\end{array}$ \\
\hline
\end{tabular}

\section{RESULTADOS}

Como resultados parciais, já que o projeto ainda está em execução e é de caráter permanente, podemos indicar que o crescente número da plateia já demonstra que o Projeto Ensino em Cena está sendo bem recebido pelo público. Ademais, foi realizado um questionário entre professores e alunos a fim de sondar como eles percebem o projeto e se o mesmo está realmente alcançando os devidos objetivos. Desse modo, foi realizado um questionário com 15 indivíduos entre 
professores e alunos do IFCE campus de Sobral contendo os seguintes questionamentos:

- Você gosta de assistir os filmes exibidos pelo Projeto Ensino em Cena?

- Para você, o filme é um recurso didático?

- Você consegue associar o filme exibido no Projeto Ensino em Cena com a realidade? Em caso afirmativo, qual a sua relação?

- Após a sessão de filme há uma explanação/debate guiado por um professor. Para você, o que significa esse momento?

Sobre as respostas obtidas para a primeira pergunta, todos os entrevistados responderam de forma positiva, como por exemplo o entrevistado JY que relatou: "Sim, acho interessante a ideia de mostrar a lógica por trás da ficção".

Com relação ao segundo questionamento não foi diferente, todos os entrevistados responderam que consideram o filme como ferramenta didática por excelência e ainda a reconhecem como metodologia de ensino, respondendo por consequência ao terceiro questionamento. Isso fica atestado nas repostas de RS: "Sim, uma relação que podemos notar é o uso da física no nosso cotidiano como vimos em 'Perdidos em marte". Já o professor GM: "A relação dos filmes com a realidade é extremamente contextualizada e com forte recurso didático". O entrevistado LD complementa: "Sim, mesmo sendo um simples filme, consegui aprender coisas interessantes, que não são debatidos em sala de aula por motivo de tempo".

O último questionamento foi feito para identificar o que a plateia acha das intervenções do professor responsável pela exibição do filme e tivemos em todas as respostas resultados semelhantes, indicando que a ideia dessa atividade vem alcançando seu objetivo de ser uma metodologia de ensino ativa a qual ajuda os alunos a realizar as abstrações e compreender a relação com nossa vida cotidiana entre a teoria cientifica e a realidade, vendo-as como uma unidade. Para enfatizar o exposto acima ML diz que: "é um momento importantíssimo para que haja um debate entre o público (alunos) e o professor, e para o professor mostrar o que realmente é teoria física de verdade e o que é ficção". 0 entrevistado AF completa com sua experiência de uma aprendizagem lúdica, facilitando a compreensão da relação teoria-prática: "É o momento que posso tirar minhas dúvidas e fazer questionamentos sobre o tema abordado e sobre a realidade, além de ser o lugar de lazer onde posso unir diversão e aprendizagem".

Por fim, JM traduz em poucas palavras o sentimento que a equipe organizadora do projeto espera alcançar ao elaborar cada uma das atividades: “Um dos momentos mais importante do projeto pois esclarece as dúvidas dos alunos e abre uma oportunidade para debates".

Diante de tudo que foi apresentado até aqui é oportuno salientar que o Projeto Ensino em Cena é reconhecido pela comunidade acadêmica do IFCE que o privilegia como uma importante ferramenta de aprendizagem, provando que, sendo bem sistematizada, é um bom recurso para auxiliar o processo de ensino e aprendizagem. 


\section{CONSIDERAÇõES FINAIS}

Com as sessões apresentadas no Ensino em Cena, observou-se que o cinema é uma forte ferramenta de entretenimento e educação, em que o espectador tem a oportunidade de viajar no tempo e no espaço, conhecendo a cultura e a realidade de diferentes figuras históricas de diferentes espaços sociais, além de vivenciar experiências que antes só poderiam acontecer na sua imaginação, como por exemplo, visitar outro planeta.

Através da divulgação desse trabalho, espera-se levar ao leitor uma reflexão sobre as inúmeras possibilidades de utilização do cinema como ferramenta lúdica para o ensino e divulgação educacional. 0 uso da sétima arte não deve ser considerado apenas como uma ferramenta complementar. $O$ uso de tal mídia deve ser entendido como uma estratégia de ensino completa, que não deixa nada a desejar com relação às estratégias mais tradicionais.

A boa recepção e a compreensão do conteúdo pelos espectadores em cada apresentação do projeto Ensino em Cena, demonstraram que ferramentas lúdicas como o cinema podem ser alternativas viáveis na luta a favor da atenção do aluno e da curiosidade do educando, destacando a sétima arte como um grande aliado no ensino e na divulgação de ciências.

Com o intuito de divulgar, difundir, incentivar e viabilizar o uso de obras cinematográficas como ferramenta pedagógica, é apresentado em anexo uma lista de títulos (além dos 13 filmes citados anteriormente) que podem ser utilizados no ensino e na divulgação de ciências. Além do título, duração, gênero e ano de lançamento do filme, apresenta-se sugestões de possíveis temas que poderão ser abordados na apresentação do longa.

\section{REFERÊNCIAS BIBLIOGRÁFICAS}

BARROS, M. D. M.; GIRASOLE, M.; ZANELLA, P. G. O uso do cinema como estratégia pedagógica para o ensino de ciências e de biologia: o que pensam alguns professores da região metropolitana de Belo Horizonte. Revista Práxis, Três Poços - Volta Redonda, ISSN online: 2176-9230, ISSN impresso: 1984-4239, 2013. Disponível em: <web.unifoa.edu.br/praxis>. Acesso em: 08 jun. 2016. CAPARRÓS-LERA, J. M.; ROSA, C. S. O cinema na escola: uma metodologia para o ensino de história. Educ. foco, Juiz de Fora, v. 18, n. 2, p. 189-210, 2013.

CARVALHAL, F. C. de A. Instituto Nacional de Cinema Educativo: da história escrita à história contada - um novo olhar. Mnemocine, 2009. Disponível em: < www.mnemocine.com.br>. Acesso em: 08 jun. 2016.

DUARTE, R. Cinema e Educação. 2. ed. Belo Horizonte: Autêntica, 2002. 128 p.

LEITE, S. Cinema brasileiro: das origens à retomada. São Paulo: Fundação Perseu Abramo, 2005. $160 \mathrm{p}$. 
SILVA, J. A. Cinema e educação: o uso de filmes na escola. Revista Intersaberes, Curitiba. v. 9, n.18, 2014. Disponível em: <www.grupouninter.com.br/intersaberes>. Acesso em: 08 jun. 2016.

VERDE, D. Do espaço imaginado ao espaço cinematográfico: alusões ao filme Trainspotting Sem Limites. 2005. 76f. Trabalho de Conclusão de Curso (Bacharel e Licenciado em Geografia) - Faculdade de Ciências e Letras, FESB - Fundação Municipal de Ensino Superior de Bragança Paulista, Bragança Paulista-SP, 2005. 